\title{
Evidence-based complementary and alternative medicine bioinformatics approach through network pharmacology and molecular docking to determine the molecular mechanisms of Erjing pill in Alzheimer's disease
}

\author{
XIYANG YANG ${ }^{1 *}$, YANG GUAN $^{1 *}$, BO YAN ${ }^{2}$, YONGYAN XIE $^{3}$, MAOFU ZHOU $^{1}$, YI WU $^{4}$, \\ LIHUA YAO $^{1,5}$, XIAOPENG QIU ${ }^{1}$, FEIXIA YAN ${ }^{1}$, YAOHUI CHEN ${ }^{6}$ and LIPING HUANG ${ }^{1}$
}

\begin{abstract}
${ }^{1}$ Department of Pharmacy, Jiangxi University of Traditional Chinese Medicine, Nanchang, Jiangxi 330004; ${ }^{2}$ Department of Research and Development, Shandong Qidu Pharmaceutical Co., Ltd., Zibo, Shandong 255400; ${ }^{3}$ Department of Traditional Chinese Medicine, Jiangxi University of Traditional Chinese Medicine, Nanchang, Jiangxi 333004; ${ }^{4}$ Department of Jiangxi Provincial Institute for Drug Control, Jiangxi Provincial Engineering Research Center for Drug and Medical Device Quality, Nanchang, Jiangxi 330006; ${ }^{5}$ Department of Life Science, Jiangxi Science and Technology Normal University, Nanchang, Jiangxi 330013; ${ }^{6}$ Department of Nephrology, Jiangxi Provincial People's Hospital, Nanchang, Jiangxi 330006, P.R. China
\end{abstract}

Received July 23, 2020; Accepted January 19, 2021

DOI: $10.3892 /$ etm.2021.10687

\begin{abstract}
Erjing pill, a Traditional Chinese Medicine (TCM) formulation composed of Polygonatum sibiricum and Lycium chinense, has an important role in the treatment of Alzheimer's disease (AD). However, the underlying mechanisms of the action of Erjing pill in AD have remained elusive. In the present study, the key ingredients of Erjing pill were investigated and the active components and their mechanisms of
\end{abstract}

Correspondence to: Professor Liping Huang, Department of Pharmacy, Jiangxi University of Traditional Chinese Medicine, 1688 MeiLing Avenue, Nanchang, Jiangxi 330004, P.R. China E-mail: jxnchlp@163.com

Professor Yaohui Chen, Department of Nephrology, Jiangxi Provincial People's Hospital, 152 AiGuo Avenue, Nanchang, Jiangxi 330006, P.R. China

E-mail: yhchendoc@163.com

*Contributed equally

Abbreviations: AD, Alzheimer's disease; TCMSP, Traditional Chinese Medicine Systems Pharmacology; DS, Discovery Studio; GO, Gene Ontology; KEGG, Kyoto Encyclopedia of Genes and Genomes; ACHE, acetylcholinesterase; BCHE, butyrylcholinesterase; APP, amyloid protein precursor; $\mathrm{A} \beta$, amyloid- $\beta$; TTD, Therapeutic Target Database; OMIM, Online Mendelian Inheritance in Man; ADMET, absorption, distribution, metabolism, excretion and toxicity; BBB, blood-brain barrier; HIA, human intestinal absorption; PPB, plasma protein binding; DBP, dibutylphthalate

Key words: Alzheimer's disease, Erjing pill, network pharmacology, molecular docking action on $\mathrm{AD}$ were analyzed based on networks pharmacology. By using the TCM and TCM Systems Pharmacology and databases, the components of Erjing pill were screened and the data were captured using Discovery Studio. The SwissTarget webserver database was used to predict the potential protein targets of Erjing pill components for pathologies related to $\mathrm{AD}$. The data were further analyzed with the disease targets of $\mathrm{AD}$ based on analysis of the Online Mendelian Inheritance in Man, DiGSeE and Therapeutic Target Database. Subsequent analysis of mechanistic pathways of the screened components and protein targets allowed us to construct a network by using Gene Ontology and Kyoto Encyclopedia of Genes and Genomes, which revealed potential molecular mechanisms of Erjing pill against AD. Finally, the protective effect of three active components on neurons was verified using an in vitro injury model of PC12 cells induced by $\mathrm{A} \beta_{25-35}$. The results indicated that 65 bioactive components of Erjing pill, including lauric acid and zederone, and 6 targets, including acetylcholinesterase, butylcholinesterase and amyloid protein precursor, were closely associated with the prevention and treatment of AD. The molecular components of Erjing pill were indicated to be involved in various biological signaling processes, mainly in synaptic signal transmission, transsynaptic signal transmission and chemical synaptic transmission. Furthermore, related pathways targeted by Erjing pill in AD included the regulation of neuroactive ligand-receptor interactions, the PI3K-Akt signaling pathway, serotoninergic synapses, calcium signaling pathways and dopaminergic synapses. A cell viability assay indicated that the compounds (polygonatine $\mathrm{A}$, polygonatine $\mathrm{C}$ and 4,5-dihydroxyflavone) assessed were able to significantly improve the survival rate and increase the $\mathrm{Ca}^{2+}$ level in a PC1 2 cell model of AD induced by amyloid- $\beta_{25-35}$. The present study revealed that the mechanisms of action of Erjing pill to prevent and treat $\mathrm{AD}$ included a multicompound, multitarget and multipathway regulatory network. 


\section{Introduction}

Alzheimer's disease (AD) is defined as progressive memory loss and cognitive dysfunction and its pathological features are the accumulation of amyloid- $\beta(\mathrm{A} \beta)$ to form senile plaques (SPs) and intracellular hyperphosphorylated Tau protein to form neurofibrillary tangles (NFTs), leading to neuronal death $(1,2)$. With global aging, the incidence of AD has been increasing year by year; the number of affected patients has doubled in the past two decades and has been estimated to reach 131.5 million by 2050 , bringing a serious economic burden to families, as well as social disruption (3). To date, the intricate etiology of the development of AD has remained to be fully elucidated, but there is evidence that both the microtubule-associated protein tau and amyloid- $\beta(\mathrm{A} \beta)$ exert complex and synergistic effects contributing to the hypometabolism and symptomatology of AD $(4,5)$. Although several therapeutic strategies have achieved results based on these hypotheses, no satisfactory treatment is available to date. Given the numerous synchronic pathways involved in the development of $\mathrm{AD}$, it is thought that therapies acting on multiple targets may be beneficial for the prevention and treatment of $\mathrm{AD}$ and will be superior to current single-target therapies against AD (6).

Traditional Chinese Medicine (TCM), which is well known for working in synergy on multiple targets and pathways, may provide novel potentially effective treatments for diseases such as AD $(7,8)$. It is recorded in the 'Inner Canon of the Yellow Emperor', the earliest medical classic in China, that in TCM, the occurrence of AD is thought to be closely associated with kidney deficiency $(9,10)$. Certain clinical studies have demonstrated that TCM syndrome in AD mainly manifests as kidney deficiency (11). Erjing pill, which is composed of Polygonatum sibiricum and Lycium chinense, was first recorded in the 'Sheng Ji Zong Lu' (12), a medical book that recorded numerous famous prescriptions and was compiled in the Song Dynasty. The Erjing pill was also recorded in numerous classic works of TCM, such as 'Pu Ji Fang' (13), 'Tai Yi Yuan Qi Xiao Liang Fang Da Quan' (14) and 'Zun Sheng Ba Jian' (13). In the clinic, Erjing pill is mainly used to protect the kidneys, delay aging and enhance immunity and memory (13). It has been used for the prevention and treatment of AD for numerous years. Its ingredients Polygonatum sibiricum and Lycium chinense are both included in the 'List of Items that Are Both Food and Drugs' issued by the Ministry of Health of China in 2002 [Ministry of Health Legal Supervision Department issued (2002) no. 51] $(15,16)$. Polygonatum sibiricum may be used to treat the reproductive system, regulate immunity and enhance brain function $(17,18)$. Lycium chinense is used as an adjuvant therapy for various clinical diseases. It is frequently used to protect the eyes and liver, treat impotence and improve memory $(19,20)$. Animal experiments have reported that Erjing pill may improve the learning and memory ability of rats induced by long-term irritation stress (21). It also significantly improved the learning and memory ability of mice with D-galactose-induced aging (22) and aluminum trichloride-induced dementia (23). Erjing pill may improve the learning and memory abilities of rats induced by $A \beta_{1-40}$ upon injection into the hippocampus, reduce the deposition of $A \beta$ and inhibit the overphosphorylation of tau protein (24). However, the clinical application of
Erjing pill for AD has been limited and remains to be further explored due to the unknown mechanism of action.

Given the characteristics of multicomponent and multitargeting of TCMs (25), it is usually a time- and cost-consuming process to pinpoint its active components and then test the experimental effects of these active components individually, as the results are easily affected by experimental animals and external factors (26). Exploring the mechanism of action of a single component commonly commences using a simplified single target, which sets substantial limitations on studies. Network pharmacology is an emerging method and strategy for drug design based on systems biology and multidirectional pharmacology (27). By constructing a complex network among drugs, targets and signal pathways, including active molecular screening, target prediction, molecular docking and network analysis, network pharmacology combines a drug-target network with a biological system network to provide novel approaches and strategies for the development of new drugs (28). The present study sought to unravel the effectiveness of Erjing pill through networks pharmacology to explore the major active components and the multi-target groups of Erjing pill in the treatment of AD. The present study also provided a systematic approach for the exploration of the molecular mechanisms of Erjing pill to provide a foundation for the application of Erjing pill as a potential TCM treatment for $\mathrm{AD}$.

\section{Materials and methods}

Databases, tools and software. The following databases, tools and software were used in the present study: The TCM (http://tcm.cmu.edu.tw/) and TCM Systems Pharmacology (TCMSP; http://lsp.nwu.edu.cn/index.php) are the networks pharmacology platforms and databases of TCM (29). UniProt (https://www.UniProt.org/) is a protein database (30). PubChem (https://pubchem.ncb i.nlm.nih.gov/) is a cheminformatics database (31). Gene Ontology (GO) is a bioinformatics platform for analyzing the biological functions of genes (32). GeneCards (https://www.genecards.org/) is an integrative website used for predicting human genes (33). The Therapeutic Target Database (TTD; https://db.idrblab.org/ttd/) (34), and the Online Mendelian Inheritance in Man (OMIM; http://www. omim.org/) (35) and DiGSeE (https://digsee.com/en/) are databases of known and exploited therapeutic proteins, as well as targeted diseases and pathways (36). Discovery Studio 4.5 (DS) is a software for structure construction (37). SwissTargetPrediction (https://www.swisstargetprediction. $\mathrm{ch} /$ ) is a chemical target prediction platform (38). Metascape (http://metascape.org/) is used for gene function analysis (39). Cytoscape 3.2.1 is a platform-independent open-source software for visualizing networks and combining them with various types of attribute data (40).

Screening of active ingredients in Erjing pill. The active ingredients in Erjing pill were screened from the literature (search terms: 'Erjing pill', 'Polygonatum sibiricum' and 'Lycium chinense'), TCMSP, Chinese chemistry database, TCM-Database@Taiwan (41) and experimental separated systematically in the present laboratory, and the collected ingredients were screened and analyzed for drug-likeness 
using DS software. Pharmacokinetic properties, including absorption, distribution, metabolism, excretion and toxicity (ADMET), are the major factors influencing biological activity. In the present study, five ADMET-related parameters, including aqueous solubility, blood-brain-barrier (BBB) penetration, human intestinal absorption (HIA), plasma protein binding (PPB) and hepatotoxicity, were employed to identify the potential bioactive components of Erjing pill. The screening criteria for active components in Erjing pill were as follows: Water-solubility parameter, 3-4; BBB penetration, 1-2; HIA, 0; PPB, FALSE; and toxicity parameter, FALSE.

Prediction of compound targets and AD-associated targets. To predict the potential targets of screened compounds in Erjing pill, two public databases, PubChem and SwissTargetPrediction, were used for identification of the compound-related targets depending on the canonical Simplified Molecular Input Line Entry System formula by limiting the species to 'Homo sapiens'.

The TTD, OMIM and DiGSeE databases were employed to identify $\mathrm{AD}$-associated targets. The standard gene names and UniProt ID of AD-related targets were obtained from the UniProtKB database as well.

GO and pathway enrichment analyses. The related targets were inputted into the Metascape platform, which is an online open source for gene annotation and analysis, for GO and pathway annotation. The amount of genes was used as the analysis standard.

Protein-protein interaction network construction. Cytoscape (version 3.2.1) software, which is an open-source bioinformatics platform for visualizing molecular interaction networks, was used to construct a 'compound-pathway-disease' network for obtaining the interacting genes between Erjing pill and AD.

Molecular docking. N-methyl-D-aspartic acid (NMDA) receptor antagonist memantine, cholinesterase inhibitor donepezil, tacrine, galanthamine and rivastigmine, are approved by the Food and Drug Administration (USA) for the treatment of AD. The English names of the drugs were used as key words, which were searched using the GeneCards platform. To obtain the highly correlative targets of drugs and compare them with the potential targets of Erjing pill for preventing and treating $\mathrm{AD}$, all processes of molecular docking were performed using DS software. The docking active pocket was defined by the original ligand molecule. Subsequently, the docking parameters were set as follows: SDS site sphere radius, 9; top hit, 3; post cluster radius, 0.5 ; and the other parameters were set to default values. The technology roadmap of the present study is presented in Fig. 1.

\section{Validation of compounds by in vitro assays}

Cell culture. The rat pheochromocytoma cell line PC12 is an internationally recognized ideal model for in vitro studies of neurobiology, neurochemistry and nervous system diseases. These cells exhibit the characteristics of neuroendocrine cells, such as exhibiting obvious synapse formation. These cells may produce neuron-associated proteins and may be stably cultured (42).
The PC12 cell line was purchased from the Shanghai Cell Bank of the Chinese Academy of Sciences. PC12 cells were cultured in RPMI 1640 medium (Gibco; Thermo Fisher Scientific, Inc.) with $10 \%$ (v/v) fetal bovine serum (Gibco; Thermo Fisher Scientific, Inc.) and 5\% (v/v) horse serum (MRC, Jiangsu, China). Cells were maintained at $37^{\circ} \mathrm{C}$ in an atmosphere containing $5 \% \mathrm{CO}_{2}$, and saturated humidity of $95 \%$.

Polygonatine A and polygonatine C extraction. According to literature (43), the air-dried Rhizomes of $P$. sibiricum [30 kg; purchased from Jiangxi Province Zhengyi Chinese Medicinal Materials Co., Ltd.; Identified as the dried rhizome of P. sibiricum, a Liliaceae plant, by professor Xiaomei FU (Jiangxi University of Traditional Chinese Medicine, China); Stored in the Herbal Medicine Laboratory of Jiangxi Provincial Institute of Drug Testing and Research] were Processed in accordance with the Regulations for processing Chinese herbal medicines in Jiangxi Province of the Polygonati Rhizoma (44) for $24 \mathrm{~h}$. Briefly, the air-dried Rhizomes of processed $P$. sibiricum were extracted using $70 \%$ ethanol, two repeats for $120 \mathrm{~min}$ both times. The ethanol extract was evaporated under reduced pressure to yield a brown residue $(2,300 \mathrm{~g})$. The residue was suspended in water and separated using dichloromethane, ethyl acetate and n-butanol in sequence at room temperature. The dichloromethane extract $(210 \mathrm{~g})$ was fractionated and subjected to a silica gel column (100-200 mesh; Petroleum Ether-Ethyl Acetate, 8:1) to produce 6 fractions (Fr.1-Fr.6). Fr.6 was further fractionated and subjected to a silica gel column (100-200 mesh; petroleum ether-ethyl acetate; 20:1, 10:1, 5:1, 2:1 and 1:1) to produce 22 fractions (Fr.6-a-Fr.6-v), Fr.6-t was further separated using semi-preparative HPLC (Semipreparative RP-HPLC column; Agilent Eclipse; XDB-C18 Semi-Prep $5 \mu \mathrm{m}, 9.4 \times 250 \mathrm{~mm}$; Agilent Technologies Inc.), with a flow rate of $3.0 \mathrm{ml} / \mathrm{min}$ and column temperature, $30^{\circ} \mathrm{C}$, using $\mathrm{MeOH}-\mathrm{H}_{2} \mathrm{O}$ (37:63) to give compound polygonatine $\mathrm{C}(28.2 \mathrm{mg})$. Repeated purification of Fr.6-v was performed using semi-preparative HPLC using $\mathrm{MeOH}-\mathrm{H}_{2} \mathrm{O}$ (11:89) to give compound Polygonatine A (50.2 mg).

Cell viability. The effects of 4',5-dihydroxyflavone (Yuanye; purity, $\geq 95 \%$ ), polygonatine A and polygonatine $\mathrm{C}$ on the $\mathrm{PC} 12$ cell line were determined by MTT assays. First, $100 \mu \mathrm{l}$ cells $\left(5 \times 10^{4}\right.$ cells $\left./ \mathrm{ml}\right)$ were seeded into a $96-$ well plate coated with poly-L-lysine (Boster Biotechnology, Inc.). After the cells attached, treatments with various concentrations of 4',5-dihydroxyflavone, polygonatine A and polygonatine C $(5,10,20$, $40,80$ or $160 \mu \mathrm{M})$ were performed for $24 \mathrm{~h}$. In the MTT assay, cells were incubated with $10 \mu \mathrm{l}$ MTT (Beijing Solarbio Science \& Technology Co., Ltd.; $5 \mathrm{mg} / \mathrm{ml}$ ) for $4 \mathrm{~h}$ at $37^{\circ} \mathrm{C}$, the supernatant was discarded and formazan was then dissolved in DMSO. Subsequently, optical density values were measured at $490 \mathrm{~nm}$ using a microplate reader (ELx800; Biotek). The effect of the three compounds on the survival rate of PC12 cells was thereby determined. In another experiment, $100 \mu 1$ cells $\left(5 \times 10^{4}\right.$ cells $\left./ \mathrm{ml}\right)$ were seeded into a $96-$ well plate coated with poly-L-lysine. After the cells attached, they were stimulated with $60 \mu \mathrm{M} \mathrm{A} \beta_{25-35}$ (Sigma-Aldrich; Merck KGaA) and then treated with different concentrations of 4',5-dihydroxyflavone, 


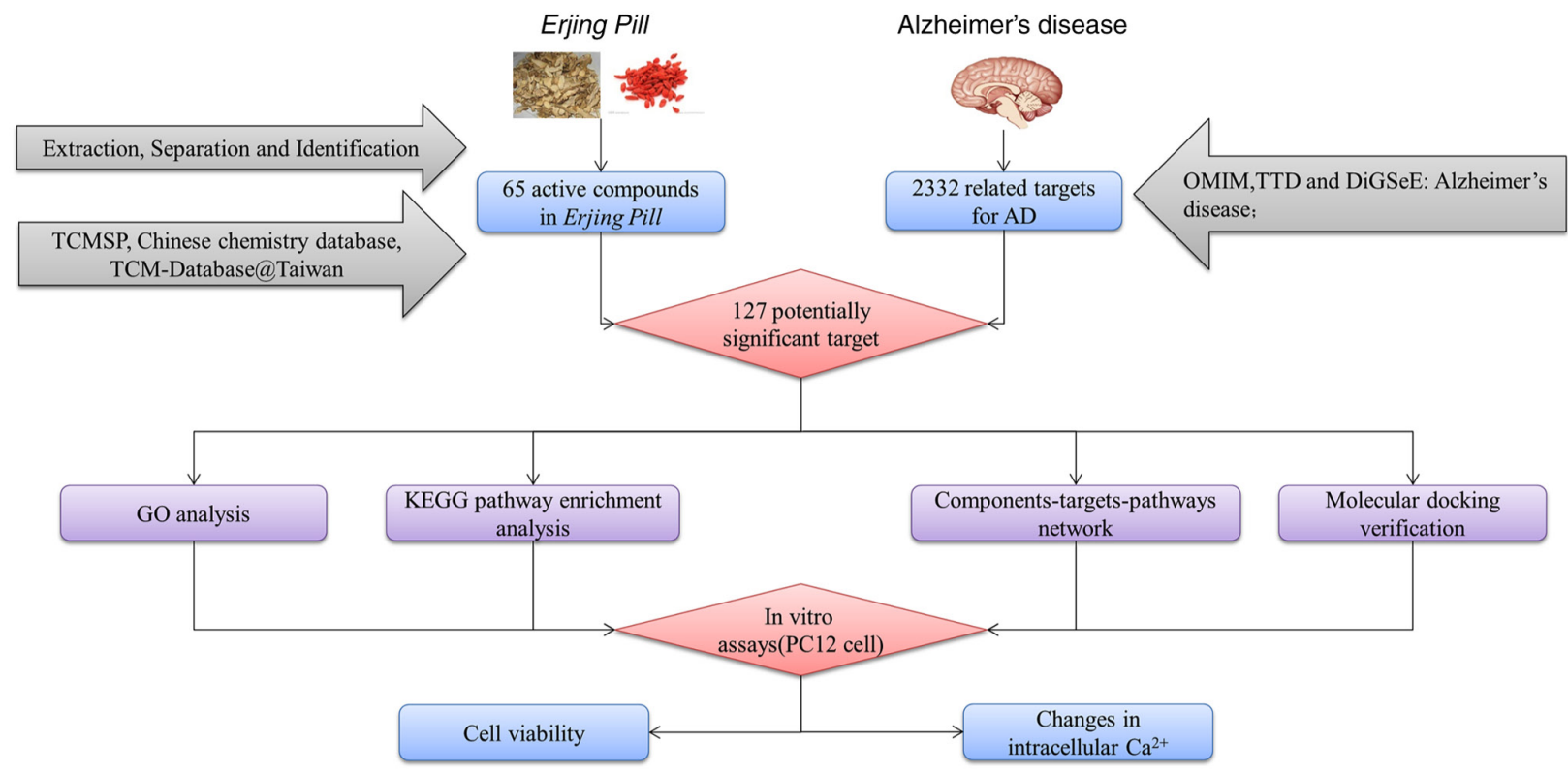

Figure 1. Scheme of the design of the present study. The complete technical roadmap was divided into three steps. The first step was to screen the active components of Erjing pill and the related targets for AD. In the second step, molecular docking technology was used to compare the potential targets for preventing and treating $\mathrm{AD}$ with approved drugs and Erjing pill. The third step was the validation of the screened compounds and the key signaling pathways based on in vitro assays. AD, Alzheimer's disease; GO, Gene Ontology; KEGG, Kyoto Encyclopedia of Genes and Genomes; TCMSP, Traditional Chinese Medicine systems pharmacology; OMIM, Online Mendelian Inheritance in Man; TTT, Therapeutic Target Database.

polygonatine A or polygonatine $\mathrm{C}(10,20$ or $40 \mu \mathrm{M})$ for $24 \mathrm{~h}$ prior to the MTT assay.

Changes in intracellular $\mathrm{Ca}^{2+}$. PC12 cells were seeded in 24-well plates at a density of $5 \times 10^{4}$ cells $/ \mathrm{ml}$ and treated with different concentrations of 4',5-dihydroxyflavone $(20 \mu \mathrm{M})$, polygonatine $\mathrm{A}(40 \mu \mathrm{M})$ or polygonatine $\mathrm{C}(20 \mu \mathrm{M})$ for $24 \mathrm{~h}$, followed by washing thrice with $10 \mathrm{mM}$ HEPES buffer (Sigma-Aldrich; Merck KGaA). Subsequently, $300 \mu$ l of Fluo 3-AM working solution (Sigma-Aldrich; Merck KGaA) was added to each well and samples were incubated for $30 \mathrm{~min}$ in the dark at $37^{\circ} \mathrm{C}$ and $5 \% \mathrm{CO}_{2}$. The cells were washed thrice with $10 \mathrm{mM}$ HEPES solution to ensure that any unbound nonspecific dye on the cell surface was washed away. Subsequently, $300 \mu \mathrm{l}$ of $10 \mathrm{mM}$ HEPES buffer was added to each well, followed by incubation for $30 \mathrm{~min}$ at $37^{\circ} \mathrm{C}$ in a cell incubator, with $5 \% \mathrm{CO}_{2}$, and subsequently, new HEPES solution was added. Finally, the fluorescence intensity was detected with a fluorescence microscope (excitation wavelength, $488 \mathrm{~nm}$ ) and the fluorescence intensity of calcium ions was analyzed using ImageJ v1.8.0 software (National Institutes of Health).

Statistical analysis. All statistical analyses were performed using SPSS 17.0 software (SPSS, Inc.). Significant differences were determined by one-way ANOVA with Dunnett's post-hoc test. Values are expressed as the mean \pm standard deviation. $\mathrm{P}<0.05$ was considered to indicate statistical significance.

\section{Results}

Identification of the main active components of Erjing pill. The active components of Erjing pill were retrieved from TCMSP, TCM-Database@Taiwan and the Chinese chemistry

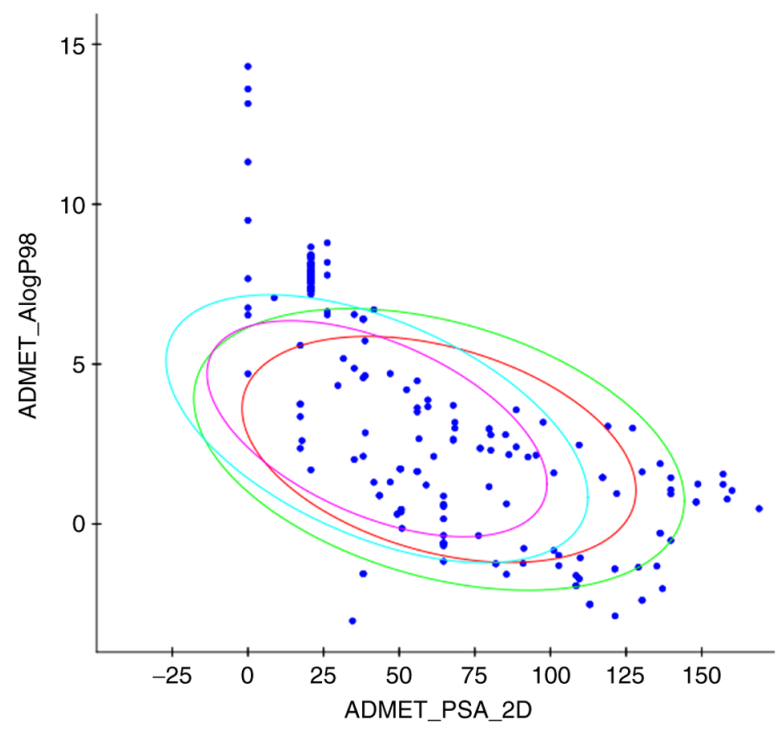

Figure 2. Prediction of ADMET using Discovery Studio. ADMET_Alog P98 represents the lipid-water partition coefficient and ADMET_PSA_2D represents the polar molecular surface area. The 2D graphs of ADMET_PSA_2D and ADMET_Alog P98 display two pairs of ellipses, representing the 95 and 99\% confidence zones of the blood-brain barrier penetration model (purple and blue) as well as the 95 and $99 \%$ confidence intervals of the human intestinal absorption model (red and green). ADMET, absorption, distribution, metabolism, excretion and toxicity; PSA, polar surface area.

database. The absorption, distribution, metabolism and excretion (ADME)-related properties of the selected ingredient are presented in Fig. 2. A total of 65 active components for AD treatment were identified using DS [Table SI $(22,23,45-52)]$.

Prediction of drug target. By using the Swiss Target Prediction platform, the potential protein targets of these 65 
A

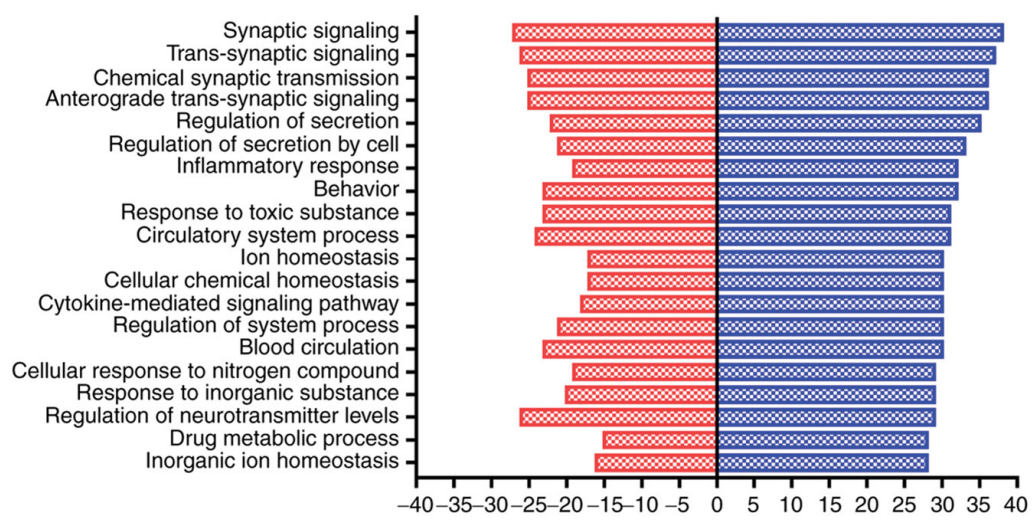

B

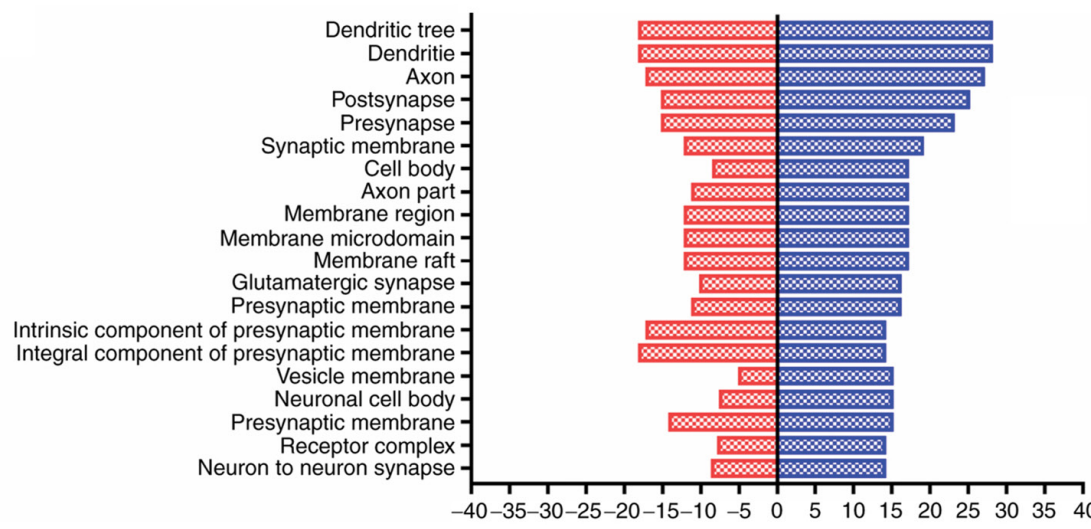

C

Phosphotransferase activity, alcohol group as acceptorcohol group as acceptor-
Protein kinase activity-
Oxidoreductase activity Kinase binding Protein kinase binding
Lipid binding Protein domain specific binding Transcription factor binding Protein serine/threonine kinase activity Protein tyrosine kinase activity$G$ protein-coupled amine receptor activityProtein heterodimerization activityNeurotransmitter receptor activity Ammonium ion binding Transcription regulatory region sequence-specific DNA binding
RNA polymerase II regulatory region DNA binding RNA polymerase II regulatory region DNA binding Phosphatase binding Phosphatidylinositol 3-kinase activity

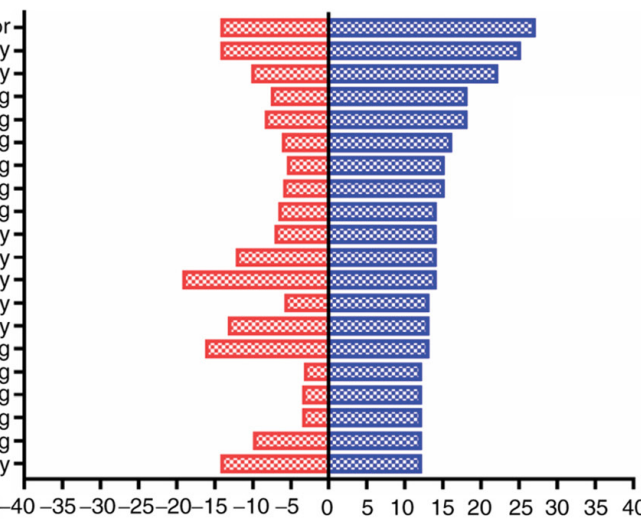

D

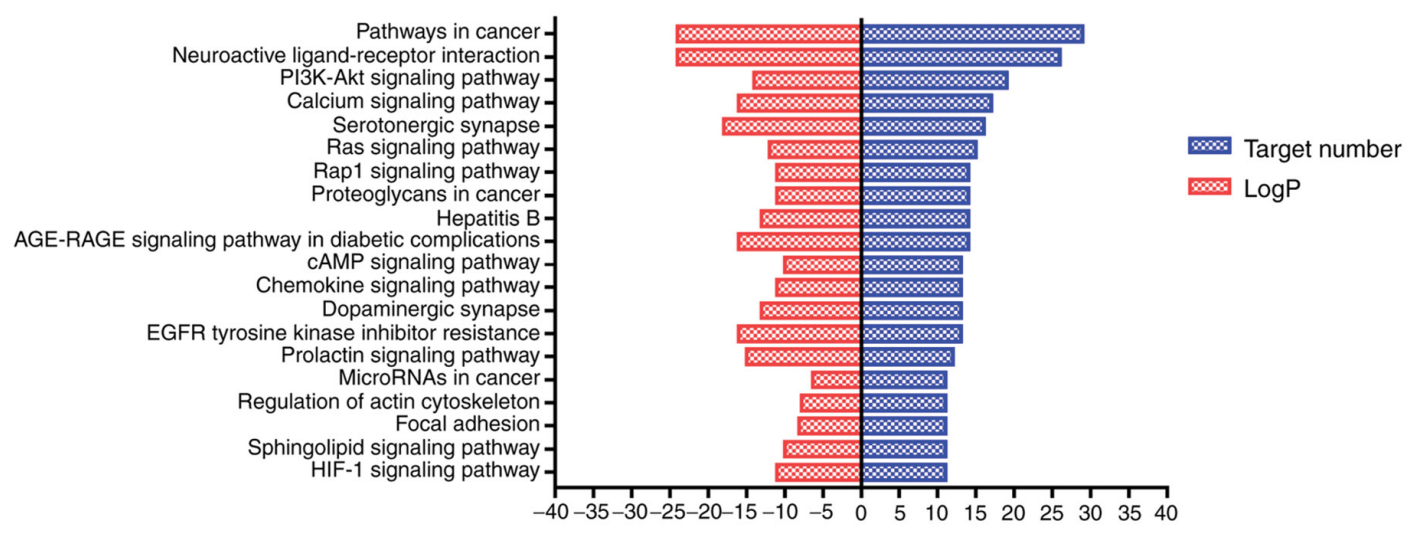

Figure 3. Enrichment analysis of potential targets from major active components of Erjing pill against Alzheimer's disease. Gene Ontology terms in the categories (A) biological process, (B) cellular component and (C) molecular function. (D) Kyoto Encyclopedia of Genes and Genomes pathways.

active components of Erjing pill were analyzed. In total, 265 potential targets were identified after eliminating duplicates. In total, 2,332 potential targets of AD-related genes were obtained using the OMIM, TTD and DiGSeE diseases and 127 potentially significant targets for the treatment of $\mathrm{AD}$ were annotated, as presented in Table SII. 
Table I. Target protein function and root mean square deviation values.

\begin{tabular}{llcr}
\hline Gene symbol & \multicolumn{1}{c}{ Protein function } & PDB ID & RMSD \\
\hline ACHE & $\begin{array}{l}\text { Terminates signal transduction at the neuromuscular junction by hydrolysis of the } \\
\text { acetylcholine released into the synaptic cleft. }\end{array}$ & 4 EY5 & 0.19 \\
BCHE & $\begin{array}{l}\text { Esterase with broad substrate specificity. Contributes to the inactivation of the } \\
\text { neurotransmitter acetylcholine. }\end{array}$ & $4 \mathrm{~B} 0 \mathrm{O}$ & 1.13 \\
& $\begin{array}{l}\text { Performs physiological functions on the surface of neurons relevant to neurite } \\
\text { growth, neuronal adhesion and axonogenesis. }\end{array}$ & $3 \mathrm{IVH}$ & 1.76 \\
& G-protein coupled receptor for 5-hydroxytryptamine (serotonin) & $4 \mathrm{IB} 4$ & 0.75 \\
HTR2A & $\begin{array}{l}\text { The muscarinic acetylcholine receptor mediates various cellular responses. } \\
\text { CHRM2 }\end{array}$ & 5ZKC & 1.11 \\
MAPT & $\begin{array}{l}\text { Promotes microtubule assembly and stability and may be involved in the } \\
\text { establishment and maintenance of neuronal polarity. }\end{array}$ & 4 Y5I & 1.23 \\
& & &
\end{tabular}

PDB, protein databank; ACHE, acetylcholinesterase; BCHE, butyrylcholinesterase; APP, amyloid protein precursor; HTR2A, 5-hydroxytryptamine receptor 2A; CHRM2, muscarinic acetylcholine receptor M2; MAPT, microtubule-associated protein tau.

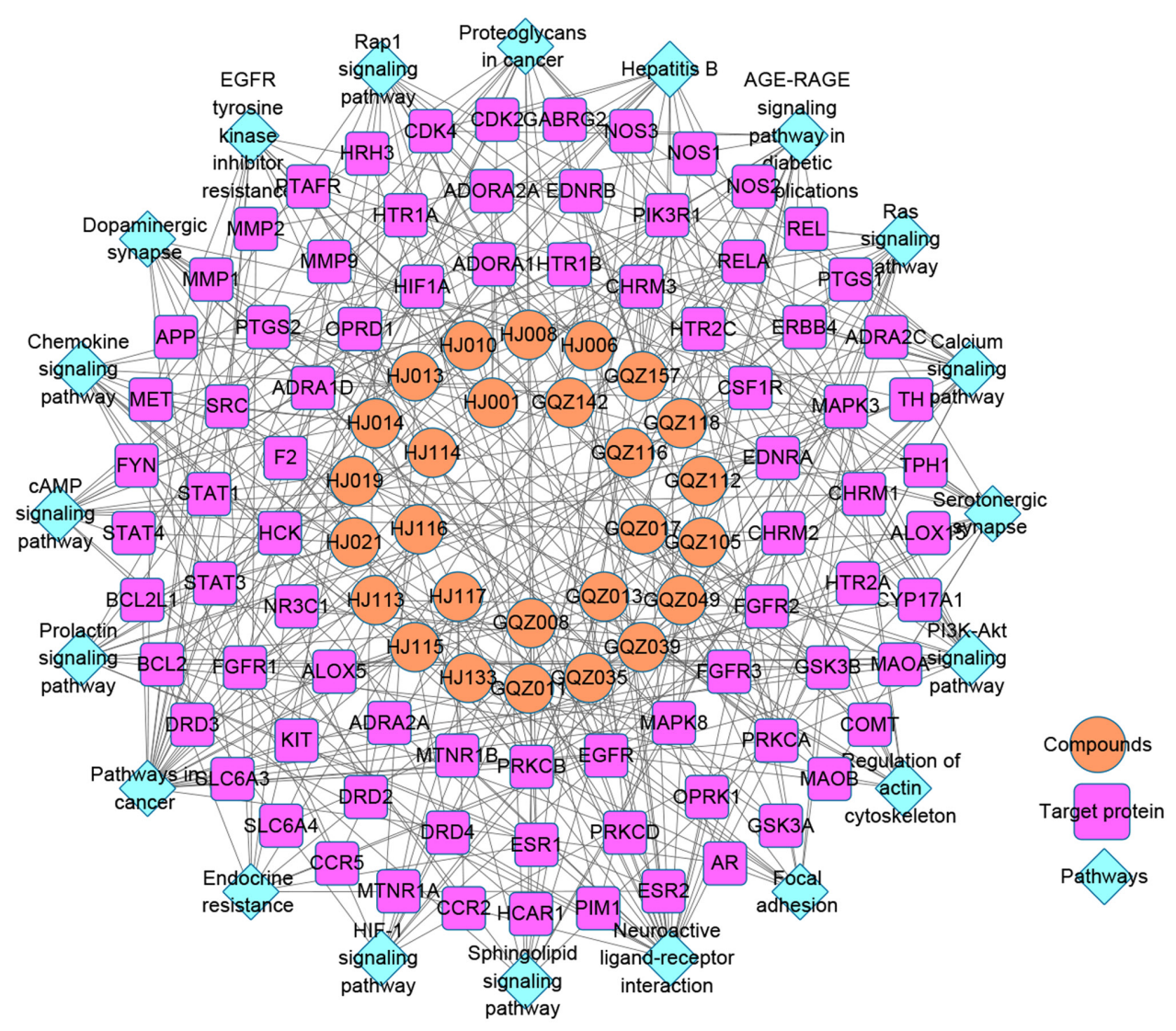

Figure 4. Compounds-targets-pathways network of Erjing pill in the treatment of Alzheimer's disease.

Signaling pathway enrichment analyses with GO and Kyoto Encyclopedia of Genes and Genomes (KEGG). To further establish the effect of the active components of Erjing pill, 127 significant target proteins of AD were analyzed. GO functional enrichment and determination of KEGG signaling pathways for both active components and target proteins were performed using the Metascape database, as presented in Fig. 3. The results of the GO analysis demonstrated that in the category biological process, enrichment was mainly in the synaptic signaling pathway in response to synaptic signal transmission, transsynaptic signal transmission, anterograde transsynaptic signal transmission, chemical synaptic transmission and secretory regulation (Fig. 3A). Furthermore, in the category cellular component, cellular response to dendrites, axons, posterior synapses, presynapses and synaptic membranes were relevant enriched terms (Fig. 3B). In the category molecular function, obvious enrichment in phosphotransferase activity, protein kinase activity, oxidoreductase activity, lipid binding and transcription factor binding was obtained (Fig. 3C). 

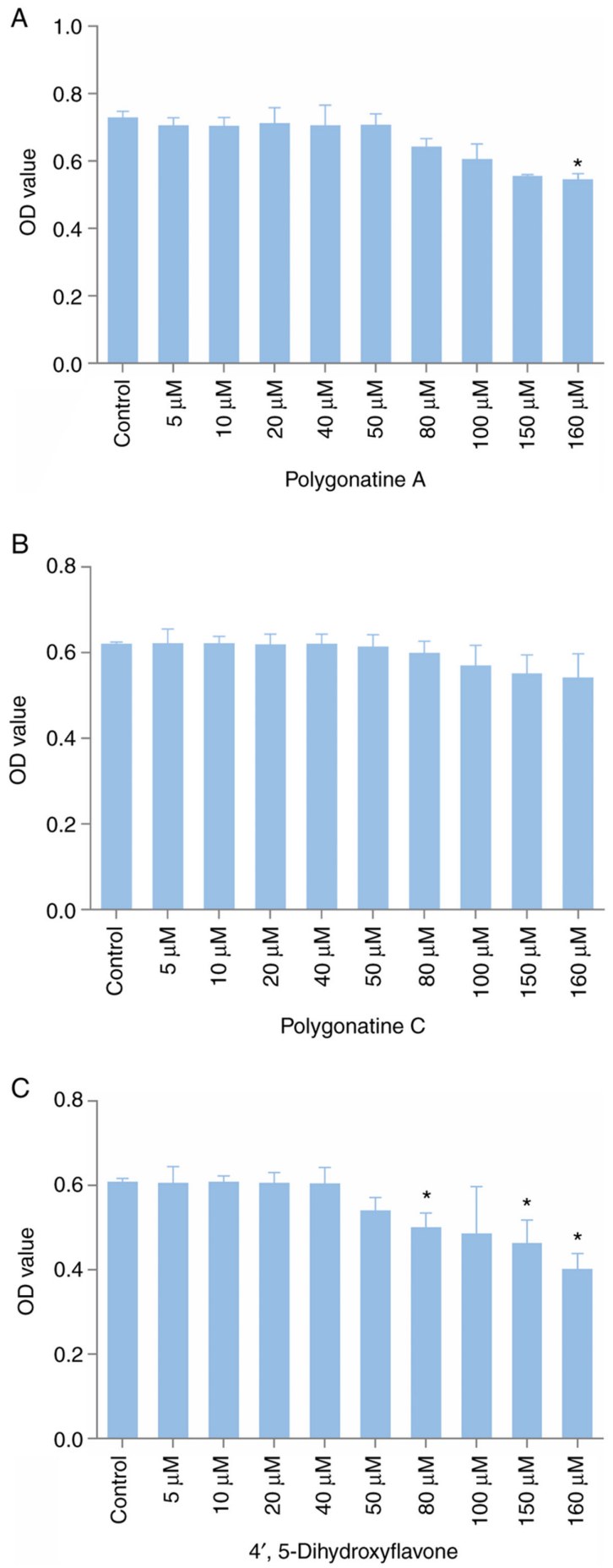

Figure 5. Effects of different concentrations of (A) polygonatine A, (B) polygonatine $\mathrm{C}$ and (C) 4',5-dihydroxyflavone on the survival rate of PC12 cells. "P<0.05 vs. control group. OD, optical density.

KEGG pathway enrichment analysis revealed 145 pathways as targets of Erjing pill for the treatment of AD, including neuroactive ligand-receptor interactions, the PI3K-Akt signaling pathway, serotoninergic synapses, the calcium ion signaling pathway and dopaminergic synapses. The pathways closely associated with the pathogenesis of AD and those with high significance are presented in Fig. 3D.

Active components-targets-pathways network of Erjing pill for the prevention and treatment of $A D$. The network map of

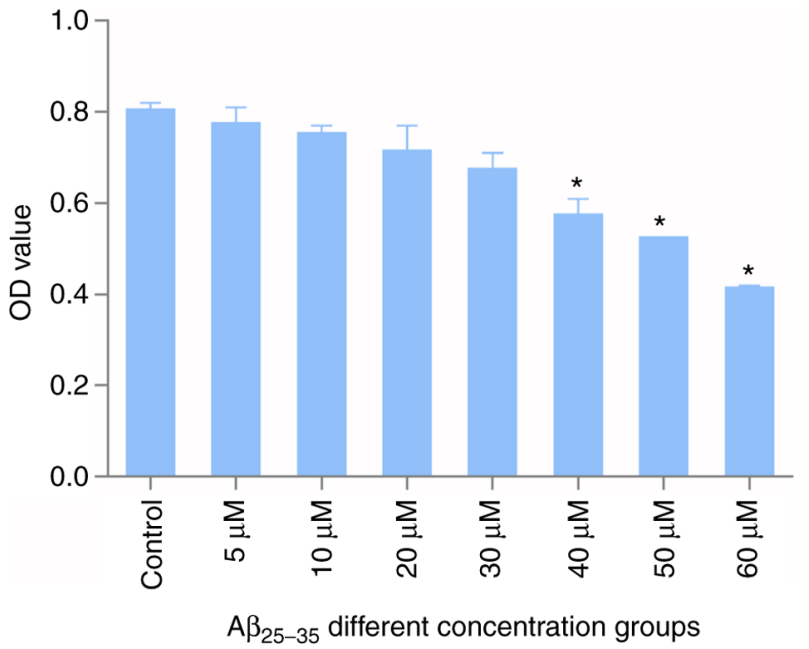

Figure 6. $\mathrm{A} \beta_{25-35}$-induced Alzheimer's disease model survival screening in PC1 2 cells. ${ }^{*} \mathrm{P}<0.05$ vs. control group. OD, optical density; $\mathrm{A} \beta$, amyloid- $\beta$.

significant components and potential AD targets of Erjing pill was constructed using the Cytoscape database (Fig. 4). The network contained 128 nodes and 378 edges in this interaction network. Central network evaluation was performed to identify the main targets. The results further demonstrated that in the prevention and treatment of $\mathrm{AD}, 27$ nodes are directly related to the target of Erjing pill, 81 nodes are indirectly related to that target and 20 nodes are the signaling pathways involved in the targeting of AD. In the network, the components with the highest degree of interaction were GQZ157 (zederone, 9), HJ021 (sibiricoside B_qt, 6), GQZ013 [dibutylphthalate (DBP), 6], GQZ035 (atropine, 6), HJ113 (2',7-dihydroxy-3',4'-dimethoxyisoflavone, 5) and GQZ017 (paeonol, 5), and the network suggested that the effect of Erjing pill on AD may be the result of multicomponent and multitargeting effects.

Molecular docking. Using the five control drugs memantine, tacrine, donepezil, galantamine and rivastigmine as keywords, the top 10 target genes were obtained using the GeneCards platform and are listed in Table SIII. Upon comparison with 127 potential targets of Erjing pill for AD, the results suggested that acetylcholinesterase (ACHE), butyrylcholinesterase (BCHE), amyloid protein precursor (APP), 5-hydroxytryptamine receptor 2A (HTR2A), muscarinic acetylcholine receptor M2 (CHRM2) and microtubule-associated protein tau (MAPT) were shared targets. The Root mean square deviation (RMSD) was $<0.2 \mathrm{~nm}$ and the results revealed that the docking method was reliable (Table I). The 2D structure of 65 active components of Erjing Pill and 5 control drugs were inputted into the DS platform using the CDOCKER module and -CDOCKER ENERGY was obtained. The results highlighted 20 compounds with better anti-AD properties compared with 4 control drugs (Table SIV).

Validation of compounds in vitro. From the aforementioned results and analysis, three compounds were selected for the assays. The results of the MTT assays are presented in Fig. 5. At low concentrations, the three compounds had no significant effect on the survival rate of PC12 cells. However, when the 


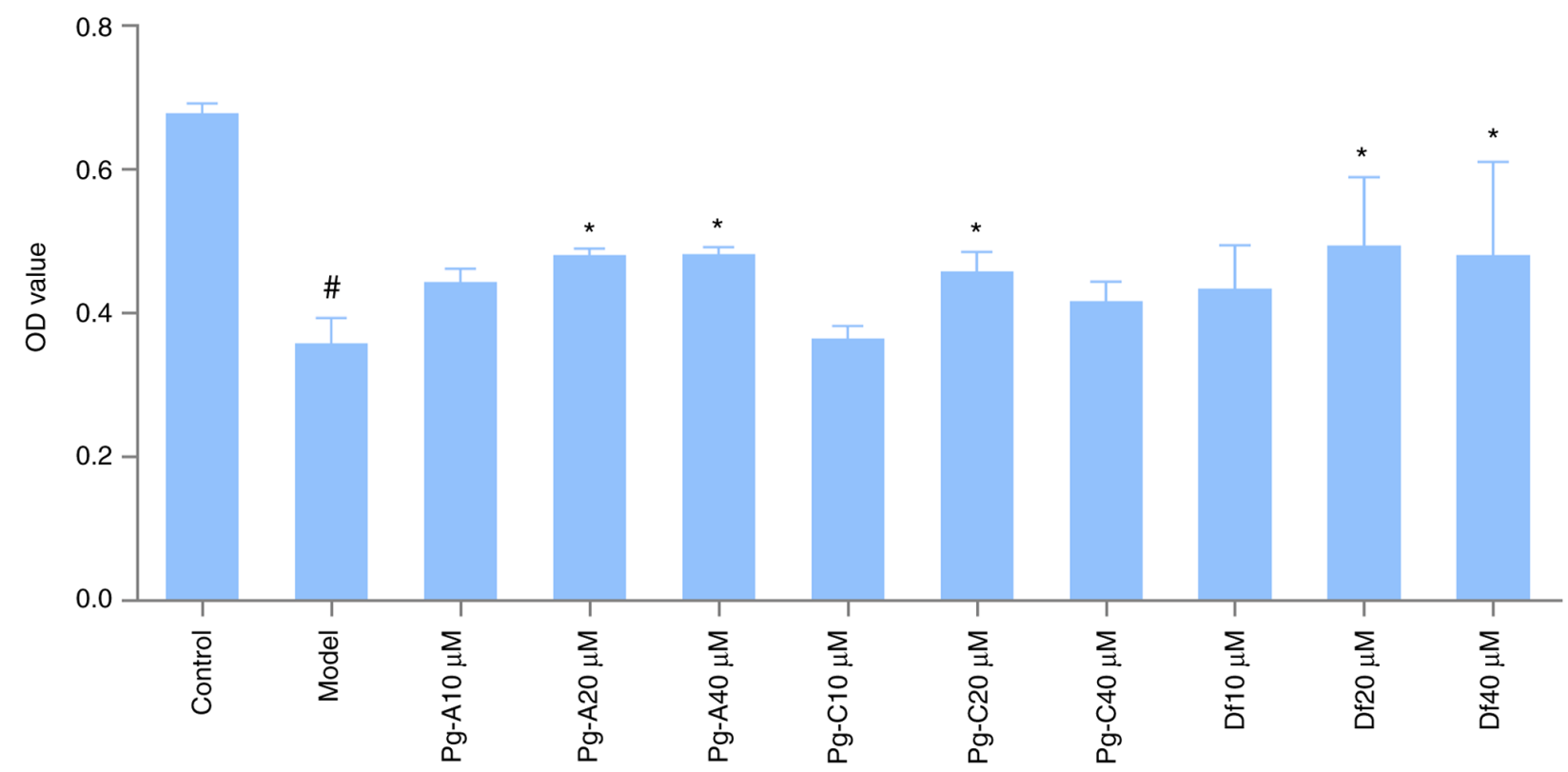

Figure 7. Effects of three compounds on the survival rate of the PC12 cell model of Alzheimer's disease induced by $\mathrm{A} \beta_{25-35} .{ }^{\#} \mathrm{P}<0.01 \mathrm{vs}$. control group; ${ }^{*} \mathrm{P}<0.05$ vs. group treated with $\mathrm{A} \beta_{25-35}$ alone. OD, optical density; Pg-A, polygonatine A; Df, 4',5-dihydroxyflavone; $\mathrm{A} \beta$, amyloid- $\beta$.

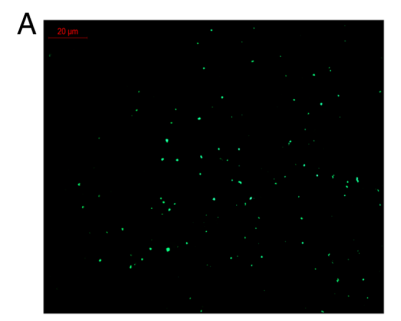

D

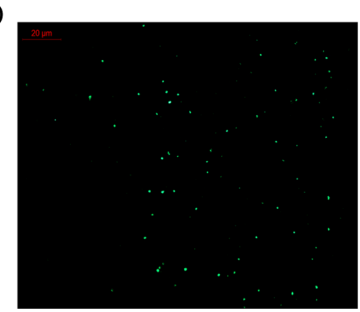

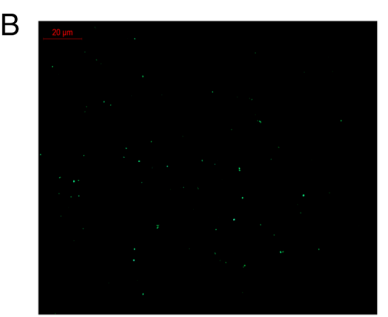

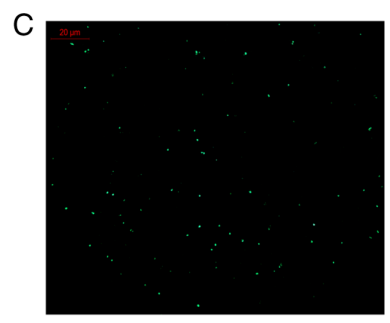

E

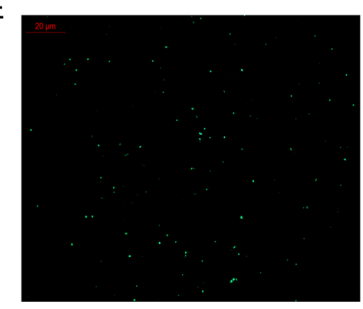

Figure 8. Effects of three compounds on $\mathrm{Ca}^{2+}$ in the PC12 cell model of Alzheimer's disease induced by amyloid- $\beta_{25-35}$. (A) Control group, (B) model group, (C) polygonatine A group, (D) polygonatine C group, (E) 4',5-dihydroxyflavone group (scale bars, $20 \mu \mathrm{m}$; magnification, x200).

concentrations of 4',5-dihydroxyflavone, polygonatine A and polygonatine $\mathrm{C}$ were $>50,80$ and $100 \mu \mathrm{M}$, respectively, the survival rate of PC12 cells exhibited a decreasing trend. To administer a gradient of doses, 10,20 and $40 \mu \mathrm{M}$ were selected as the doses of the three compounds.

The results of establishing the AD cell model are presented in Fig. 6. Compared with that in the control group, the 24-h survival rate of cells in the $A \beta_{25-35}$ groups decreased with increasing drug concentrations. When the concentration of the modeling drug was $60 \mu \mathrm{M}$, the cell inhibition rate was $42 \%$. Therefore, the optimal modeling concentration was selected as $60 \mu \mathrm{M}$.

The effects of the three compounds on the survival rate of the PC12 cell model of AD induced by $\mathrm{A} \beta_{25-35}$ are presented in Fig. 7. Compared with that in the control group, the cell survival rate in the model group was significantly reduced.
Under the microscope, the cells in the model group appeared more shrunken, the cell refractive index was increased, and certain cells floated, indicating that the modeling was successful (data not shown). Compared with that in the model group, the survival rate of PC12 cells in the polygonatine A 20 and $40 \mu \mathrm{M}$ groups was significantly increased $(\mathrm{P}<0.05)$. The survival rate of the polygonatine $\mathrm{C} 20 \mu \mathrm{M}$ dose group was also significantly increased $(\mathrm{P}<0.05)$ and the survival rates of the 4'5-dihydroxyflavone 20 and $40 \mu \mathrm{M}$ dose groups were significantly increased compared with that of the model group $(\mathrm{P}<0.05)$.

Changes in intracellular $\mathrm{Ca}^{2+}$ are presented in Fig. 8 and Table II. Compared with that in the control group, the intracellular $\mathrm{Ca}^{2+}$ level in the model group was significantly reduced $(\mathrm{P}<0.01)$. Compared with those in the model group, $\mathrm{Ca}^{2+}$ levels in the polygonatine A $40 \mu \mathrm{M}$ group, polygonatine C $20 \mu \mathrm{M}$ 
Table II. Effects of Erjing pill monomer compounds on $\mathrm{Ca}^{2+}$ fluorescence in the Alzheimer's disease model of PC12 cells induced by amyloid- $\beta_{25-35}$.

\begin{tabular}{lcc}
\hline Group & $\begin{array}{c}\text { Concentration } \\
(\mu \mathrm{M})\end{array}$ & $\begin{array}{c}\text { Fluorescence } \\
\text { intensity }\end{array}$ \\
\hline Control & - & $3,473.00 \pm 358.86$ \\
Model & - & $1,172.25 \pm 30.74^{\mathrm{a}}$ \\
Polygonatine A & 40 & $2,883.00 \pm 32.14^{\mathrm{b}}$ \\
Polygonatine C & 20 & $2,972.33 \pm 230.91^{\mathrm{b}}$ \\
4',5-Dihydroxyflavone $^{\prime}$ & 20 & $2,542.75 \pm 309.52^{\mathrm{b}}$ \\
\hline
\end{tabular}

${ }^{\mathrm{a}} \mathrm{P}<0.01$ vs. Control; ${ }^{\mathrm{b}} \mathrm{P}<0.05$ vs. model group.

group and 4',5-dihydroxyflavone $20 \mu \mathrm{M}$ group were significantly increased $(\mathrm{P}<0.05)$.

\section{Discussion}

As a neurodegenerative disease, $\mathrm{AD}$ is the most common cause of senile dementia. With the rapid global aging process, the incidence of AD has been exhibiting annual increases, which has provided challenges in the pharmacology, nursing and elderly care sectors (53). Current single-target drugs may relieve the symptoms of $\mathrm{AD}$, but the effect is unsatisfactory and requires to be improved further. The therapeutic advantages of TCM with its multicomponent and multitarget properties have begun to receive widespread attention (54). Erjing pill, a famous classic prescription composed of Polygonatum sibiricum and Lycium chinense, may be traced back to the 'Sheng Ji Zong Lu' in the Northern Song Dynasty (A.D. 1117) and has the effect of nourishing the kidneys and promoting intellectual performance. Studies have demonstrated that Erjing pill is able to remedy impairments in the learning and memory ability of rats induced by long-term irritation stress (55) and significantly improve cognitive impairment of mice induced by aluminum trichloride (56), as well as thyroxine combined with reserpine (57). However, the mechanisms of action of Erjing pill on AD have remained elusive and further research is necessary. In the present study, with the application of network pharmacological technology, the targets were identified and analyzed via active components, and an interaction network was constructed. In addition, functional enrichment analysis provided terms and pathways that are of importance in the prevention and treatment of AD by Erjing pill. Furthermore, molecular docking techniques were adopted to validate key nodes of the network. The results of previous studies clearly indicated a correlation between multiple active components and multiple targets of diseases. Thus, unraveling such a pharmacological network may provide a scientific basis for the development of effective strategies to treat $\mathrm{AD}$.

In the present study, a combination of compound target prediction and disease target databases/tools was used to compare the 265 potential targets screened by the SwissTarget prediction platform with 2,332 targets obtained by screening disease databases, such as OMIM and TTD. As a result, 127 common targets, including APP and phosphoinositide-3-kinase regulatory subunit 1 (PIK3R1), were obtained, all of which may be correlated with the prevention and treatment of AD. GO analysis results from the Metascape database revealed that these 127 target proteins are mainly related to synaptic signaling, transsynaptic signaling, dendrites, axons and other signaling pathways. By comparing the control drug targets retrieved by the GeneCards platform with the potential targets of Erjing pill, common targets, including ACHE, BCHE, APP, HTR2A, CHRM2 and MAPT, were identified. Previous studies have demonstrated the following: i) In the brains of patients with AD, ACHE activity in SP and NFTs are significantly increased, affecting the release of choline neurotransmitters and leading to the formation of $\mathrm{A} \beta$ deposition and NFTs, resulting in a vicious cycle. Inhibition of ACHE activity to improve the $\mathrm{ACH}$ content in the brain may relieve the symptoms of patients with $\mathrm{AD}(58)$; ii) the development of $\mathrm{BCHE}$ inhibitors may increase the hydrolysis of neurotransmitter acetylcholine by acetylcholinesterase to lower synaptic levels and induce $\mathrm{BCHE}$ overexpression to improve the symptoms of AD (59); iii) APP has a fundamental relationship with the pathogenesis of AD. APP is a precursor protein of $A \beta$, which produces $A \beta$ through continuous hydrolysis of $\beta$-secretase and $\gamma$-secretase (60). Reducing the expression of APP and changing the activity of secretase may decrease $A \beta$ production, thereby helping to prevent the excessive deposition of $A \beta$ to form SP; iv) The 5HT-2A receptor is a serotonin receptor subtype. As a type of G-protein-coupled receptor, these receptors are located in the central nervous system and exhibit functions related to neurotransmitter transmission, such as cognition, learning and memory. The change in the 5HT-2A receptor exhibits a correlation with mental symptoms in patients with AD (61); v) mediating muscarinic $\mathrm{ACH}$ receptors that inhibit a variety of cellular responses, such as adenylate cyclase (AC) and phosphoinositide, affecting phospholipase C (PLC) activity and increasing the calcium ion concentration; thus, increasing synaptic signal transmission improves the cognitive, learning and memory functions of patients with AD (62). vi) Tau protein is a protein with numerous functions, such as connecting microtubules in axons and maintaining the stability of the microtubule assembly process. Under pathological conditions, abnormally phosphorylated Tau proteins lose the ability to transport microtubules, causing a large amount of intracellular deposition of Tau proteins to form NFTs, which leads to cognitive impairment in patients with AD (63). Thus, inhibiting the hyperphosphorylation of Tau protein represents another treatment for improving the clinical manifestations of AD. The active components in Erjing pill may increase the contents of $\mathrm{ACH}, \mathrm{BCH}$ and serotonin among neurons by six proteins, including $\mathrm{ACHE}, \mathrm{BCHE}$ and $\mathrm{APP}$, to reduce the production of $A \beta$ and the hyperphosphorylation of Tau proteins and thus prevent AD.

Using the Metascape database for KEGG pathway analysis, 127 target proteins of Erjing pill were identified as being involved in the prevention and treatment of $\mathrm{AD}$, and these proteins mainly participate in signaling pathways involved in neuroactive ligand-receptor interactions and dopaminergic synapses, including the PI3K-Akt signaling pathway and other existing pathogenesis pathways of AD (64). The anastomotic pathway also contains signaling pathways involved in the pathogenesis of neuropathic diseases, such as serotonin synapse (65) and dopamine synapse formation. Studies 
have demonstrated that 5 -HT receptor blockade induces $\mathrm{ACH}$ release, regulates the balance between glutamate and gamma-aminobutyric acid, and has a wide-ranging effect on neurotransmission and neuronal activity $(66,67)$. A study using the early AD genetic mouse model ( $\mathrm{Tg} 2576)$ (68) discovered that the degeneration of dopamine neurons in the ventral tegmental area was closely correlated with AD progression, thus confirming the relevance of dopamine levels for AD (69). Erjing pill may increase the amount of dopamine receptors and the content of dopamine in the brain, promote synapse formation, improve synaptic excitatory transmission and thus prevent AD. In previous research by our group, an AD model was established by D-galactose (i.p.) combined with $A \beta_{1-40}$ (i.c.v.) to observe the pharmacodynamic effects of Erjing pill on AD. Comparison of data from a proteomics analysis (70), with the network pharmacology screening pathways indicated that dopaminergic synapses were the most involved proteins. Existing research indicates that in the dopaminergic synapse pathway, the D1 receptor is able bind to the glutamine synthetase protein, activate $\mathrm{AC}$ and increase cAMP, which subsequently increases the level of proteinase $\mathrm{A}$, and the increase of protein kinase $\mathrm{A}$ (PKA) may accelerate the physiological and biochemical processes. On the other hand, dopamine may activate D1 receptormediated PLC-dependent calcium burst calcium flow, thereby participating in phosphoinositide metabolism and $\mathrm{Ca}^{2+}$ signal transduction process and thus having a role in promoting synapse production (71). The expression of D1 receptor mRNA in 8-month-old transgenic female mice with AD was increased compared with that of wild-type female mice of the same month of birth. Immunohistochemical staining revealed that the amount of D1 receptor in the CA1 area of the mouse exhibited an increasing trend, but there was no significant difference in the expression of D2 receptor, which indicates that the expression of $\mathrm{D} 1$ receptor is increased in AD model mice. The mechanism of action is related to the activation of AC, cAMP and PKA (72). Given that Erjing pill has the effect of increasing the expression of Gq-protein (Gq), PLC, inositol 1,4,5-triphate receptor (IP3R) and calmodulin-dependent protein kinase $2 \mathrm{~d}$ (Camk2d), Erjing pill may act through the TH-DA-D1-Gq-PLC-IP3R-CaM-Camk2d pathway in the dopaminergic synapse pathway, increasing the content of $\mathrm{Ca}^{2+}$ between cells, and has the effect of promoting the transmission of synapses in the brain.

Using the ADMET descriptors module in DS software, 302 chemical constituents collected from three databases, including TCMSP, were screened for 65 potential active components, including lauric acid, zederone, DBP, polysaccharides, flavonoids and alkaloids. Using molecular docking technology, it was indicated that 20 active ingredients, such as lauric acid and paeono, exhibited improved binding to disease-related proteins compared with control drugs. Studies suggested that lauric acid (73), paeonol (74), isolecin (75), phenylalanine tocopherin (76), tryptophane (77) and DBP (78) exhibit correlations with $\mathrm{AD}$. There are 7 components that both act on the dopaminergic synapse pathway and are better than the four control drug docking results. The 7 components include DBP, paeonol, tyrosine, apigenin, 4',5-dihydroxyflavone, polygonatine $\mathrm{A}$ and polygonatine $\mathrm{C}$. Literature verification indicated that in addition to tyrosine, which is involved in the dopamine synaptic pathway, DBP, paeonol (74) and apigenin (79) act on DA receptors and promote DA production, whereas 4',5-dihydroxyflavone, polygonatine $\mathrm{A}$ and polygonatine $\mathrm{C}$ have not been previously reported. Therefore, the activity was were verified by detecting the effects of 4',5-dihydroxyflavone, polygonatine $\mathrm{A}$ and polygonatine $\mathrm{C}$ on the intracellular $\mathrm{Ca}^{2+}$ levels in an AD model generated from PC12 cells. The results indicated that 4',5-dihydroxyflavone, polygonatine $\mathrm{A}$ and polygonatine $\mathrm{C}$ significantly improved the survival rate of PC12 cells challenged with $\mathrm{A} \beta_{25-35}$ and increased the intracellular $\mathrm{Ca}^{2+}$ concentration in the PC12 cells of the AD model. Thus, the extract of Erjing pill may exert a neuroprotective effect through the dopaminergic synapse pathway.

In conclusion, in the present study, the biologically active components of Erjing pill on AD were analyzed by networks pharmacology and molecular docking. The results provided 65 active components of Erjing pill, including lauric acid, zederone and DBP, which may act on 127 protein targets, such as APP and PIK3R1, and through multiple protein functions, such as synaptic signal transmission and chemical synaptic transmission. In addition, multiple pathways, such as neuroactive ligand-receptor interactions and dopaminergic synapses, appear to be involved, further suggesting that Erjing pill is a multiple component-multiple target-multiple pathway to prevent and treat Alzheimer's disease. Subsequently, 4',5-dihydroxyflavone, polygonatine $\mathrm{A}$ and polygonatine $\mathrm{C}$ were selected to verify the results of the networks pharmacology analysis through in vitro tests. The results indicated that the tested compounds are able to significantly increase the survival rate of PC12 cells injured by $\mathrm{A} \beta_{25-35}$ and increase the $\mathrm{Ca}^{2+}$ concentration in PC12 cells in the AD model. The present study preliminarily elucidated the active components and mechanism of Erjing pill in preventing and treating $\mathrm{AD}$ and provided a direction for follow-up research on the scientific mechanisms of action of Erjing pill in the treatment of AD.

\section{Acknowledgements}

Not applicable.

\section{Funding}

This work was supported by the Academic and Technical Leader Program of Jiangxi Province (grant nos. 20182BCB2 2005 and 20165BCB18006), the Natural Science Foundation of Jiangxi Province (grant nos. 20171BAB205083 and 2017 2BCB22010), the National Natural Science Foundation of China (grant nos. 82060759, 31660275 and 31960193), the Jiangxi Provincial Health and Family Planning Commission for Chinese Medicine Research Project (grant no. 2016A023), Jiangxi Provincial Traditional Chinese Medicine First-class Discipline Special Research Fund (grant nos. JXSYLXK-Z HYAO119 and JXSYLXK-ZHYAO137), Project of Science and Technology Department of Jiangxi Province (grant nos. 20165BCB18006 and 20172BCB22010), Postgraduate Innovation Fund Project of Jiangxi University of Traditional Chinese Medicine (grant no. JZYC20S03) and Funds from China Scholarship Council (grant no. 201808360274). The funders had no role in the design of the study or the 
collection, analysis, interpretation of data or preparation of the manuscript.

\section{Availability of data and materials}

The datasets used and/or analyzed during the current study are available from the corresponding author on reasonable request.

\section{Authors' contributions}

$X Y$ and $Y G$ designed the research and wrote the original draft. $\mathrm{BY}$ and YX performed the software analysis. MZ, YW and FY performed the formal analysis. LY and XQ performed the cell experiments and date curation. YC and LH performed the data analysis and reviewed the manuscript. YC and LH confirm the authenticity of all the raw data. All authors read and approved the final manuscript.

\section{Ethics approval and consent to participate}

Not applicable.

\section{Patient consent for publication}

Not applicable.

\section{Competing interests}

The authors declare that they have no competing interests.

\section{References}

1. Blennow $\mathrm{K}$, Hampel $\mathrm{H}$, Weiner $\mathrm{M}$ and Zetterberg $\mathrm{H}$ : Cerebrospinal fluid and plasma biomarkers in Alzheimer disease. Nat Rev Neurol 6: 131-144, 2010.

2. Kozlov S, Afonin A, Evsyukov I and Bondarenko A: Alzheimer's disease: As it was in the beginning. Rev Neurosci 28: 825-843, 2017.

3. Bonet-Costa V, Pomatto LC and Davies KJ: The proteasome and oxidative stress in Alzheimer's Disease. Antioxid Redox Signal 25: 886-901, 2016.

4. Nisbet RM, Polanco JC, Ittner LM and Götz J: Tau aggregation and its interplay with amyloid- $\beta$. Acta Neuropathol 129: 207-220, 2015.

5. Myeku N, Clelland CL, Emrani S, Kukushkin NV, Yu WH, Goldberg AL and Duff KE: Tau-driven 26S proteasome impairment and cognitive dysfunction can be prevented early in disease by activating cAMP-PKA signaling. Nat Med 22: 46-53, 2016.

6. Zeng Q, Li L, Siu W, Jin Y, Cao M, Li W, Chen J, Cong W, Ma M, Chen K and Wu Z: A combined molecular biology and network pharmacology approach to investigate the multi-target mechanisms of Chaihu Shugan San on Alzheimer's disease. Biomed Pharmacother 120: 109370, 2019.

7. Li C, Zhang WY, Yu Y, Cheng CS, Han JY, Yao XS and Zhou H: Discovery of the mechanisms and major bioactive compounds responsible for the protective effects of gualou xiebai decoction on coronary heart disease by network pharmacology analysis. Phytomedicine 56: 261-268, 2019.

8. Zhang Q, Li R, Peng W, Zhang M, Liu J, Wei S, Wang J, Wu C, $\mathrm{Gao} \mathrm{Y}$ and $\mathrm{Pu} \mathrm{X}$ : Identification of the active constituents and significant pathways of guizhi-shaoyao-zhimu decoction for the treatment of diabetes mellitus based on molecular docking and network pharmacology. Comb Chem High Throughput Screen 22: 584-598, 2019.

9. Du YJ, Tao YM, Tian Q, Wang Y, Wang L and Wu WH: Based on the ERK/CREB signal pathway to explore the mechanism of moxibustion on Shenshu points to improve neuron loss in ovariectomized AD rats with D-galactose. Chin J Trad Chin Med: 1-18, 2020 (In Chinese).
10. Gao YY and Wang X: The effect of 'Kidney and Brain Xiangji' electroacupuncture on the behavior and expression of IL-1b and TNF-íA in Alzheimer's disease model mice. Shanghai J Acupuncture 39: 359-364, 2020.

11. Hao da C and Xiao PG: Network pharmacology: A rosetta stone for traditional Chinese medicine. Drug Dev Res 75: 299-312, 2014.

12. Liu Q, Bai SF, Lai XJ, Wang HF, Liang J and Lai WY: Comparison of two methods for determination of polysaccharides in Erjing pill. Chin J Exp Trad Chin Med 16: 32-34, 2010.

13. Ding C, Luo J, Shu H, Zhang XY, He GX and Zhou Y: A summary of the health effects of Shengji Erjing Recipe and analysis of its industrialization direction. Hubei J Trad Chin Med 34: 73-74, 2012.

14. Bai SF, Lai XJ, Liu Q and Lai WY: Study on the effect of Erjing pill polysaccharide on reducing blood sugar in diabetic rats. China Mod Appl Pharm 27: 577-580, 2010.

15. Li SX: Understanding and suggestions on the variety list of 'Food and Medicine'. Chin J Nat Med 4: 232-242, 2001.

16. Xie GZ, Liu H, Wang Z, Tang XY and Zhang SH: Comparison of Polygonatum odoratum and Polygonatum odoratum, a traditional Chinese medicine for food and medicine. Mod Chin Med 22: 1447-1152, 2020.

17. Han C, Zhu Y, Yang Z, Fu S, Zhang W and Liu C: Protective effect of Polygonatum sibiricum against cadmium-induced testicular injury in mice through inhibiting oxidative stress and mitochondria-mediated apoptosis. J Ethnopharmacol 261: 113060, 2020.

18. Tu MF and Ye WF: Research progress of pharmacological effects and clinical application of Polygonatum sibiricum. J Yichun Univ 40: 27-31, 2018 (In Chinese).

19. Gao Y, Wei Y, Wang Y, Gao F and Chen Z: Lycium barbarum: A traditional Chinese herb and a promising anti-aging agent. Aging Dis 8: 778-791, 2017

20. Chen LG: Analysis of pharmacological effect and clinical application value of wolfberry. The World's Latest Medical Information Digest 15: 92, 2015 (In Chinese).

21. Zhang R, Zhu X, Bai H and Ning K: Network pharmacology databases for traditional Chinese medicine: Review and assessment. Front Pharmacol 10: 123, 2019.

22. Ahn MJ, Kim CY, Yoon KD, Ryu MY, Cheong JH, Chin YW and Kim J: Steroidal saponins from the rhizomes of Polygonatum sibiricum. J Nat Prod 69: 360-364, 2006.

23. Yu HS, Zhang J, Kang LP, Han LF, Zou P, Zhao Y, Xiong CQ, Tan DW, Song XB, Yu K and Ma BP: Three new saponins from the fresh rhizomes of Polygonatum kingianum. Chem Pharm Bull (Tokyo) 57: 1-4, 2009.

24. Chen YH, Yan B, Guan Y and Liu YQ: Effect of Erjing Pills on learning and memory abilities of AD rats with kidney yin deficiency induced by ovariectomy+D-galactose combined with A $\beta 1-40$. Trad Chin Drug Res Clin Pharmacol 30: 1421-1427, 2019.

25. Leng EL, Cao ZW, Jiang ZH, Zhou H and Liu L: Network-based drug discovery by integrating systems biology and computational technologies. Brief Bioinform 14: 491-505, 2013.

26. Che CT, Wang ZJ, Chow MS and Lam CW: Herb-herb combination for therapeutic enhancement and advancement: Theory, practice and future perspectives. Molecules 18: 5125-5141, 2013.

27. Zhao S and Iyengar R: Systems pharmacology: Network analysis to identify multiscale mechanisms of drug action. Annu Rev Pharmacol Toxicol 52: 505-521, 2012.

28. Zeng Q, Li L, Jin Y, Chen Z, Duan L, Cao M, Ma M and Wu Z: A network pharmacology approach to reveal the underlying mechanisms of Paeonia lactiflora pall. On the treatment of Alzheimer's Disease. Evid Based Complement Alternat Med 2019: 8706589, 2019.

29. Ru J, Li P, Wang J, Zhou W, Li B, Huang C, Li P, Guo Z, Tao W, Yang Y, et al: TCMSP: A database of systems pharmacology for drug discovery from herbal medicines. J Cheminform 6: 13, 2014.

30. UniProt Consortium: UniProt: A hub for protein information. Nucleic Acids Res 43 (Database Issue): D204-D212, 2015.

31. Hähnke VD, Kim S and Bolton EE: PubChem chemical structure standardization. J Cheminform 10: 36, 2018.

32. Gene Ontology Consortium: Gene ontology consortium: Going forward. Nucleic Acids Res 43 (Database Issue): D1049-D1056, 2015. 
33. Safran M, Dalah I, Alexander J, Rosen N, Iny Stein T, Shmoish M, Nativ N, Bahir I, Doniger T, Krug H, et al: GeneCards version 3: The human gene integrator. Database (Oxford) 2010: baq020, 2010.

34. Li YH, Yu CY, Li XX, Zhang P, Tang J, Yang Q, Fu T, Zhang X, Cui X, Tu G, et al: Therapeutic target database update 2018: Enriched resource for facilitating bench-to-clinic research of targeted therapeutics. Nucleic Acids Res 46 (D1): D1121-D1127, 2018.

35. Amberger JS and Hamosh A: Searching online mendelian inheritance in man (OMIM): A knowledgebase of human genes and genetic phenotypes. Curr Protoc Bioinformatics 58: 1.2.1-1 $2.12,2017$.

36. Kim J, So S, Lee HJ, Park JC, Kim JJ and Lee H: DigSee: Disease gene search engine with evidence sentences (version cancer). Nucleic Acids Res 41 (Web Server Issue): W510-W517, 2013.

37. Liu X, Shi Y, Deng Y and Dai R: Using molecular docking analysis to discovery Dregea sinensis Hemsl. Potential mechanism of anticancer, antidepression, and immunoregulation. Pharmacogn Mag 13: 358-362, 2017

38. Daina A and Zoete V: Application of the SwissDrugDesign online resources in virtual screening. Int J Mol Sci 20: 4612, 2019.

39. Qiao B, Wu Y, Li X, Xu Z, Duan W, Hu Y, Jia W, Fan Q and Xing H: A network pharmacology approach to explore the potential mechanisms of Yifei Sanjie formula in treating pulmonary fibrosis. Evid Based Complement Alternat Med 2020: 8887017, 2020 .

40. Lotia S, Montojo J, Dong Y, Bader GD and Pico AR: Cytoscape app store. Bioinformatics 29: 1350-1351, 2013.

41. Chen CY: TCM Database@Taiwan: The world's largest traditional Chinese medicine database for drug screening in silico. PLoS One 6: e15939, 2011

42. Su WT and Shi YA: Nanofiber containing carbon nanotubes enhanced PC12 cell proliferation and neuritogenesis by electrical stimulation. Biomed Mater Eng 26 (Suppl 1): S189-S195, 2015.

43. Ning HH, Yuan MM, Wu QP, Ping YH, Zhou ZQ, Xu Y, Wu Y and Yin HX: Separation and identification of chemical constituents of Polygonatum multiflorum. Chin J Exp Formulas 24: $77-82,2018$.

44. Yi BX,Zhong LY and Gong QF: Jiangxi Jianchang's special Wen method and its modern research ideas. Lishizhen Trad Chin Med 23: $1755-1756,2012$

45. Chen H, Feng SS and Sun YJ: Research progress on chemical constituents and pharmacological activities of three kinds of medicinal Huangjing. Chin Herbal Med 46: 2329-2338, 2015.

46. Ma K, Huang XF and Kong LY: Steroidal saponins from Polygonatum cyrtonema. Chem Nat Compd 49: 888-891, 2013.

47. Yu HS, Ma BP, Kang LP, Zhang T, Jiang FJ, Zhang J, Zou P, Zhao Y, Xiong CQ, Tan DW, et al: Saponins from the processed rhizomes of Polygonatum kingianum. Chem Pharm Bull (Tokyo) 57: 1011-1014, 2009.

48. Yu HS, Ma BP and Song XB: Two new steroidal saponins from the processed Polygonatum kingianum. Helv Chim Acta 93 1086-1092, 2010

49. Nakanishi $\mathrm{T}$, Inada $\mathrm{A}$, Kambayashi $\mathrm{K}$ and Yoneda $\mathrm{K}$ : Flavonoid glycosides of the roots of Glycyrrhiza uralensis. Phytochemistry 24: 339-341, 1985.

50. Aida K, Tawata M, Shindo H, Onaya T, Sasaki H, Yamaguchi T, Chin $\mathrm{M}$ and Mitsuhashi $\mathrm{H}$ : Isoliquirigenin: A new aldose reductase inhibitor from glycyrrhizae radix. Planta Med 56: 254-258, 1990.

51. Sun LR, Li X and Wang SX: Two new alkaloids from the rhizome of Polygonatum sibiricum. J Asian Nat Prod Res 7: 127-130, 2005.

52. Wang YF, Lu CH, Lai GF, Cao JX and Luo SD: A new indolizinone from Polygonatum kingianum. Planta Med 69: 1066-1068, 2003.

53. Chiquita S, Rodrigues-Neves AC, Baptista FI, Carecho R, Moreira PI, Castelo-Branco M and Ambrósio AF: The retina as a window or mirror of the brain changes detected in Alzheimer's disease: Critical aspects to unravel. Mol Neurobiol 56: 5416-5435, 2019.

54. Ma J, Chen X, Bian YQ, Chen ZJ, Qiao YJ and Zhang YL: Study on efficacy markers of Salviae Miltiorrhizae Radix et Rhizoma for promoting blood circulation and remving blood stasis based on systematic traditional Chinese medicine. Zhongguo Zhong Yao Za Zhi 45: 3259-3265, 2020 (In Chinese).

55. Xu XQ, Huang JY, Zhao T, Tu XY, Huang BB, Gao SL, Xiao BQ, Luo L and Zhao XF: Mechanism of total polysaccharides from Erjing Pill against learning and memory impairment in rats with long-term stress. J Jiangxi College Trad Chin Med 19: 54-57, 2007.
56. Huang JY, Zhou J, Wei H, Tu XY and Lou LY: Pharmacological experimental study of compound Erigo against Alzheimer's Disease. J Jiangxi Med College 41: 53-56, 2001.

57. Xu XQ, Huang JY, Luo R, Xiao BQ, Zhao T and Tu XY: Effect of the effective fraction of Erjing Pill on learning and memory impairment in rats with kidney-yin deficiency model and its molecular mechanism. Chin Trad Herbal Drugs 38: 564-569, 2007.

58. Capatina L, Todirascu-Ciornea E, Napoli EM, Ruberto G, Hritcu L and Dumitru G: Thymus vulgaris essential oil protects zebrafish against cognitive dysfunction by regulating cholinergic and antioxidants systems. Antioxidants (Basel) 9: 1083, 2020.

59. Baumann K, Kordić L, Močibob M, Šinko G and Tomić S: Synthesis and in vitro screening of novel heterocyclic $\beta$-d-Glucoand $\beta$-d-galactoconjugates as butyrylcholinesterase inhibitors Molecules 24: 2833, 2019.

60. Galvão F Jr, Grokoski KC, Silva BB, Lamers ML and Siqueira IR The amyloid precursor protein (APP) processing as a biological link between Alzheimer's disease and cancer. Ageing Res Rev 49: 83-91, 2019.

61. Craig D, Donnelly C, Hart D, Carson R and Passmore P: Analysis of the 5HT-2A T102C receptor polymorphism and psychotic symptoms in Alzheimer's disease. Am J Med Genet B Neuropsychiatr Genet 144B: 126-128, 2007.

62. Ma LQ, Liu C, Wang F, Xie N, Gu J, Fu H, Wang JH, Cai F, Liu J and Chen JG: Activation of phosphatidylinositol-linked novel D1 dopamine receptors inhibits high-voltage-activated Ca2+ currents in primary cultured striatal neurons. J Neurophysiol 101: 2230-2238, 2009

63. DeTure MA and Dickson DW: The neuropathological diagnosis of Alzheimer's disease. Mol Neurodegener 14: 32, 2019.

64. Park HJ, Kwon H, Lee JH, Cho E, Lee YC, Moon M, Jun M, Kim DH and Jung JW: $\beta$-Amyrin ameliorates Alzheimer's disease-like aberrant synaptic plasticity in the mouse hippocampus. Biomol Ther (Seoul) 28: 74-82, 2020.

65. Ledo JH, Azevedo EP, Beckman D, Ribeiro FC, Santos LE, Razolli DS, Kincheski GC, Melo HM, Bellio M, Teixeira AL, et al: Cross talk between brain innate immunity and serotonin signaling underlies depressive-like behavior induced by Alzheimer's Amyloid- $\beta$ oligomers in mice. J Neurosci 36: 12106-12116, 2016

66. de Jong IEM and Mørk A: Antagonism of the 5-HT(6) receptor-Preclinical rationale for the treatment of Alzheimer's disease. Neuropharmacology 125: 50-63, 2017

67. Ferrero H, Solas M, Francis PT and Ramirez MJ: Serotonin $5-\mathrm{HT}_{6}$ receptor antagonists in Alzheimer's disease: Therapeutic rationale and current development status. CNS Drugs 31: 19-32, 2017.

68. Krashia P, Nobili A and D'Amelio M: Unifying hypothesis of dopamine neuron loss in neurodegenerative diseases: Focusing on Alzheimer's disease. Front Mol Neurosci 12: 123 , 2019.

69. Nardone R, Höller Y, Thomschewski A, Kunz AB, Lochner P, Golaszewski S, Trinka E and Brigo F: Dopamine differently modulates central cholinergic circuits in patients with Alzheimer disease and CADASIL. J Neural Transm (Vienna) 121: 1313-1320, 2014

70. Huang LP, Yang XY, Yan B and Qiu XP: Effect of Erjing Pill on hippocampal proteomics of $\mathrm{AD}$ rats with kidney yin deficiency induced by ovariectomy $+\mathrm{D}$-galactose combined with $\mathrm{A} \beta$ (1-40). Chin J Exp Pharmacol 26: 15-22 2020.

71. Sun BJ and Ling H: Research progress on the relationship between dopamine receptors and Alzheimer's disease. J Clin Ration Use 8: 177-180, 2015.

72. Lian YX and He L: Therapeutic effects of dopamine D1 receptor agonists on central nervous system diseases and their target pathways. J of Clin Rational Use 6: 102-103, 2013 (In Chinese)

73. Nafar F, Clarke JP and Mearow KM: Coconut oil protects cortical neurons from amyloid beta toxicity by enhancing signaling of cell survival pathways. Neurochem Int 105: 64-79, 2017.

74. Han F, Xu H, Shen JX, Pan C, Yu ZH, Chen JJ, Zhu XL, Cai YF and Lu YP: RhoA/Rock2/Limk1/cofilin1 pathway is involved in attenuation of neuronal dendritic spine loss by paeonol in the frontal cortex of D -galactose and aluminum-induced Alzheimer's disease-like rat model. Acta Neurobiologiae Experimentalis 80: 225-244, 2020

75. Li BL, Li X and Li JC: Metabolomics study on serum of Tg2576 micetransgenic model of Alzheimer's disease. Chin JExp Anim 25: 218-224, 2017. 
76. Sethiya NK, Nahata A, Singh PK and Mishra SH Neuropharmacological evaluation on four traditional herbs used as nervine tonic and commonly available as Shankhpushpi in India. J Ayurveda Integr Med 10: 25-31, 2019.

77. Liu X: Study on the limiting rate enzyme of tryptophan metabolism IDO1 and its inhibitors. Chem Life 6: 774-782, 2016.

78. Preciados M, Yoo C and Roy D: Estrogenic endocrine disrupting chemicals influencing NRF1 regulated gene networks in the development of complex human brain diseases. Int J Mol Sci 17: 2086, 2016
79. Nakazawa T, Yasuda T,Ueda J and Ohsawa K: Antidepressant-like effects of apigenin and 2,4,5-trimethoxycinnamic acid from perilla frutescens in the forced swimming test. Biol Pharm Bull 26: 474-480, 2003.

cc) (i) () $($ This work is licensed under a Creative Commons Attribution-NonCommercial-NoDerivatives 4.0 International (CC BY-NC-ND 4.0) License. 